\title{
An input relaxation model for evaluating congestion in fuzzy DEA
}

\author{
Hooshang Kheirollahi ${ }^{1}$, Peyman Hessari ${ }^{2}$, Vincent Charles ${ }^{3, \dagger}$ and \\ Rasoul Chawshini ${ }^{4}$ \\ ${ }^{1}$ Kurdistan University of Medical Sciences, Sanandaj, Iran \\ E-mail: 〈Hooshang.kh@gmail.com〉 \\ ${ }^{2}$ Department of Mathematical and Statistical Sciences, University of Alberta \\ 116 St. and 85 Ave., Edmonton, AB, T6G 2G1, Canada \\ E-mail: 〈p.hessari@gmail.com〉
}

${ }^{3}$ CENTRUM Católica Graduate Business School, PUCP Calle Daniel Alomía Robles 125 - 129, Los Álamos de Monterrico, Santiago de Surco, Lima 33, Peru E-mail: 〈vcharles@pucp.pe〉

${ }^{4}$ Kurdestan Electricity Power Distribution Company, Janbazan St., Sanandaj, Kurdistan Province, Iran

E-mail: 〈marsul295@gmail.com〉

\begin{abstract}
This paper develops a BCC input relaxation model for identifying input congestion as a severe form of inefficiency of decision-making units in fuzzy data envelopment analysis. The possibility approach is presented to obtain the models equivalent to fuzzy models. We use a one-model approach to determine input congestion based on the $\mathrm{BCC}$ input relaxation model. A numerical example is given to illustrate the proposed model and identify the congestion with precise and imprecise data. The proposed model is also used to determine the congestion in 16 hospitals using four fuzzy inputs and two fuzzy outputs with a symmetrical triangular membership function.
\end{abstract}

Keywords: fuzzy data envelopment analysis (FDEA), congestion, relaxed inputs

Received: September 12, 2016; accepted: July 18, 2017; available online: November 30, 2017

DOI: 10.17535 /crorr.2017.0025

\section{Introduction}

Data envelopment analysis (DEA) is a mathematical programming technique for evaluating the relative performance of decision-making units (DMUs), widely used in almost every field, such as agriculture, banking, benchmarking, economy, edu-

\footnotetext{
$\dagger$ Corresponding author 
cation, environment, government, health, human resources, information technology, insurance, manufacturing, marketing, operations, public policy, regulation, retail, services, and tourism, having emerged as a powerful management science tool [3]. DEA was introduced by Charnes, Cooper, and Rhodes [4], and the first model in DEA was called the CCR model. Banker, Charnes, and Cooper [1] added the convex constraint to the CCR model and developed a new model that was called the BCC model.

Dealing with uncertainty is unavoidable in modelling and measuring performance. Incorporating uncertainty in DEA modelling has been introduced by many researchers. Recent details can be found in Charles and Kumar [2], Shiraz, Charles, and Jalalzadeh [30], and Tsolas and Charles [32].

One of the recent interests is focusing on discussing congestions in DEA modelling, under uncertain environments. Input congestion, as a severe form of technical inefficiency, has been investigated by many researchers and different models have been employed in DEA to identify the source of the input congestion and estimate its values with crisp and imprecise data. For example, Cooper et al. [9] proposed a one-model approach for determining technical inefficiency and congestion in the inputs of DMUs with associated measures in DEA. Cooper et al. [11] extended the ordinary DEA models for identifying and determining the input congestion to chance-constrained programming approaches with stochastic inputs and outputs in DEA. Kheirollahi et al. [19] used a BCC input relaxation model to identify the input congestion of Iranian hospitals using stochastic DEA with chance-constrained programming approaches. Flegg and Allen [15] applied DEA models to analyze and determine the input congestion in new British universities. Noura et al. [27] introduced a new method, called Noura's approach, to identify and determine the amount of the input congestion of DMUs in DEA. Noura's approach requires considerably fewer computations when compared to the other models. Färe and Grosskopf [14] focused on clarifying the distinction between the approaches to modeling technology and measuring congestion, differentiating between weak disposability and the law of variable proportions. Finally, Saljooghi and Rayeni [29] investigated a methodology to measure the undesirable output congestion, as well as the input congestion, from both theoretical and empirical perspectives. To this end, they applied their proposed approach to identify congestion and measure the undesirable output in the Sistan and Baluchistan University's educational departments in Iran.

Traditionally, DEA models require accurate and crisp data, since DEA is a methodology focused on the frontier of production possibility set (PPS). A few changes in the data can change the efficient frontier significantly. Therefore, some authors proposed fuzzy approaches to assess the efficiency of homogeneous DMUs, determining the congestion and estimating the returns to scale. For instance, Khodabakhshi, Gholami, and Kheirollahi [22] used an additive model to provide an alternative approach for estimating the returns to scale in both stochastic DEA 
and fuzzy DEA. Lertworasirikul et al. [25] introduced the possibility, credibility, and necessity approaches to solve fuzzy DEA models. They explained that by using the possibility, credibility, and necessity approaches, the relationship between the primal and dual models of the fuzzy BCC models is revealed and fuzzy efficiency can be constructed. Khodabakhshi and Hejrizadeh [23] developed the fuzzy version of the input relaxation model by using some ranking methods based on the comparison of $\alpha$-cuts. Rostamy-Malkhalifeh et al. [28] proposed a new approach for determining the input congestion of DMUs with fuzzy inputs and outputs. Hosseinzadeh Lotfi et al. [16] used the one-model approach to estimate the input congestion in five Iranian banks, with two stochastic inputs and two outputs. A review of the different approaches to identifying the input congestion of DMUs in DEA can be found in Khodabakhshi, Hosseinzadeh Lotfia, and Aryavash [24].

The aim of the present paper is to determine the input congestion of DMUs using a BCC input relaxation model with precise and imprecise data. The possibility approach is used to convert the nonlinear model to a linear model. We assume that there are $\mathrm{n}$ DMUs, $\mathrm{DMUj}, j=1,2, \ldots, n$, wherein each of them produces $\mathrm{s}$ nonnegative different outputs $y_{r j}(r=1,2, \ldots, s)$, using $\mathrm{m}$ nonnegative different inputs $x_{i j}(\mathrm{I}=1,2, \ldots, \mathrm{m})$. Sometimes, in evaluating the performance of the DMUs, we need to decrease some inputs and increase other inputs to increase outputs. To this end, the BCC input relaxation model is applied as follows [17, 21]:

$$
\begin{gathered}
\text { Maximize } \quad \phi+\varepsilon\left(\sum_{i=1}^{m} s_{i 1}^{-}-\sum_{i=1}^{m} s_{i 2}^{+}+\sum_{r=1}^{s} s_{r}^{+}\right) \\
\text {Subject to } \sum_{j=1}^{n} \lambda_{j} y_{r j}-y_{r o}-s_{r}^{+}=0, \quad r=1,2, \ldots, s, \\
\sum_{j=1}^{n} \lambda_{j} x_{i j}+s_{i 1}^{-}-s_{i 2}^{+}=x_{i o}, \quad i=1,2, \ldots, m, \\
\sum_{j=1}^{n} \lambda_{j}=1, \\
s_{i 1}^{-}, s_{i 2}^{+}, s_{r}^{+}, \lambda_{j} \geq 0, i=1,2, \ldots, m ; r=1,2, \ldots, s ; j=1,2, \ldots, n .
\end{gathered}
$$

In the above model, the symbol $j=0$ designates one of the DMUj as the DMUo to be evaluated relative to all the data (including the data on $\mathrm{DMUj}=\mathrm{DMU}$ ), where $\phi \geq 1$ is a real number. The term $\varepsilon$ in the objective function of model (1) is a non-Archimedean, which is smaller than any positive real number, and which is used in order to optimize the slacks and ensure that all of the slacks are 
considered in the optimal solution. The variables $s_{i 1}^{-}$and $s_{i 2}^{+}$are the slacks for the decrement and increment of the $\mathrm{i}^{\text {th }}$ input, respectively. Finally, $s_{r}^{+}$is a slack for the increment of the $\mathrm{r}^{\text {th }}$ output.

Definition 1 (Efficiency): DMUo is efficient under model (1) if the following conditions are satisfied:

1) $\phi^{*}=1$;

2) $s_{i 1}^{-^{*}}=s_{i 2}^{+^{*}}=s_{r}^{+^{*}}=0$; for $i=1,2, \ldots, m$ and $r=1,2, \ldots, s$.

Here and hereafter $*$ is used to designate an optimal value.

The rest of this article is organized as follows: In Section 2, the definition of congestion and the one-model approach based on the relaxed combination of inputs for determining congestion are provided, along with a numerical example in the subsequent Section 3. Section 4 develops the one-model approach to the BCC input relaxation model with the triangular fuzzy data. A fuzzy numerical example is also presented in Section 5 to evaluate the efficiency and determine the congestion via a fuzzy BCC input relaxation model. The proposed model is then applied to identify the input congestion of 16 hospitals by using fuzzy inputs and outputs with a symmetrical triangular membership function. Conclusions are provided in Section 7 .

\section{Congestion}

Congestion, as the severe form of inefficiency, occurs when the excessive amounts of input cause a reduction in the output of DMUs. Researchers have investigated the input congestion of DMUs with precise and imprecise inputs and outputs, in the literature. Among the advantages of identifying and managing congestion, we can mention the increase in output, as well as the elimination of the increase in the input of DMUo. In DEA, many models have been introduced to identify input congestion of DMUs. The most famous model, which is called the one-model approach, was introduced by Cooper et al. [11]. This model was then expanded into the $\mathrm{BCC}$ input relaxation model.

In this paper, the one-model approach to the BCC input relaxation model is applied to identify the input congestion with fuzzy inputs and outputs and the possibility approach is used to obtain the deterministic models equivalent to the fuzzy models. Cooper et al. [10] defined congestion as follows:

Definition 2 (Congestion): Congestion is present in the performance of DMUo, the DMU being evaluated, when input increases give rise to decreases in the outputs that are maximally attainable or, conversely, when input decreases are accompanied by increases in the output amounts that are maximally attainable. 
We propose a $\mathrm{BCC}$ input relaxation model for identifying the congestion of the DMUs, following Cooper et al. [10]:

$$
\text { Maximize } \quad \phi+\varepsilon\left(\sum_{r=1}^{s} s_{r}^{+}-\sum_{i=1}^{m} s_{i}^{-c}-\sum_{i=1}^{m} s_{i 2}^{+}\right)
$$

$$
\begin{gathered}
\text { Subject to } \quad \sum_{j=1}^{n} \lambda_{j} y_{r j}-y_{r o}-s_{r}^{+}=0, \quad r=1,2, \ldots, s, \\
\sum_{j=1}^{n} \lambda_{j} x_{i j}+s_{i}^{-c}-s_{i 2}^{+}=x_{i o}, \quad i=1,2, \ldots, m, \\
\sum_{j=1}^{n} \lambda_{j}=1, \\
s_{i}^{-c}, s_{i 2}^{+}, s_{r}^{+}, \lambda_{j} \geq 0, i=1,2, \ldots, m ; r=1,2, \ldots, s ; j=1,2, \ldots, n .
\end{gathered}
$$

The congestion amount of the input of $\mathrm{DMUj}_{2} j=1,2, \ldots, n$, is represented by $s_{i}^{-c^{*}}$ in model (2), in accordance with the following theorem [20].

Theorem 1: Congestion is present if and only if in the optimal solution $\left(\phi^{*}, \lambda^{*}, s_{i}^{-c^{*}}, s_{i 2}^{+^{*}}, \mathrm{~s}_{\mathrm{r}}^{+^{*}}\right)$ of model (2), at least one of the following conditions is satisfied:

1) $\phi^{*}>1$ and there is at least one $\mathbf{s}_{i}^{-c^{*}}>0$, for $i=1,2, \ldots, m$;

2) There exists at least one $\mathbf{s}_{\mathrm{r}}^{+^{*}}>0$, for $r=1,2, \ldots, s$, also one $\mathbf{s}_{i}^{-c^{*}}>0$, for $i=$ $1,2, \ldots, m$.

Both the conditions of Theorem 1 tell us that DMUo is inefficient. That is, if a DMU has input congestion, then it is inefficient, but the reverse is not true. 


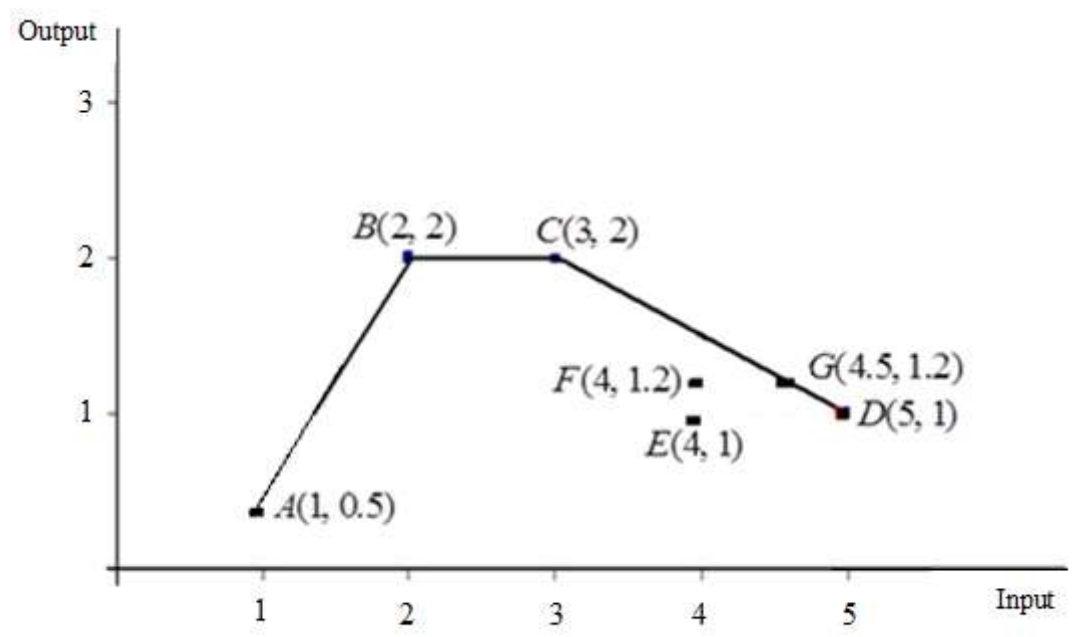

Figure 1: Input congestion

\section{Numerical example}

Now, we use the BCC input relaxation model (2) to identify the input congestion of the DMUs A, B, C, D, E, F, and G, as depicted in Figure 1. These DMUs apply one input to produce one output. For point A in Figure 1, we apply model (2) to obtain the following problem:

$$
\begin{array}{ll}
\text { Maximize } & \phi+\varepsilon\left(s^{+}-s^{-c}-s_{12}^{+}\right) \\
\text {Subjectto } & 0.5 \lambda_{A}+2 \lambda_{B}+2 \lambda_{C}+\lambda_{D}+\lambda_{E}+1.2 \lambda_{F}+1.2 \lambda_{G}-s^{+}=0.5 \phi \\
& 1 \lambda_{A}+2 \lambda_{B}+3 \lambda_{C}+5 \lambda_{D}+4 \lambda_{E}+4 \lambda_{F}+4.5 \lambda_{G}+s^{-c}-s_{12}^{+}=1 \\
& \lambda_{A}+\lambda_{B}+\lambda_{C}+\lambda_{D}+\lambda_{E}+\lambda_{F}+\lambda_{G}=1 \\
& \lambda_{A}, \lambda_{B}, \lambda_{C}, \lambda_{D}, \lambda_{E}, \lambda_{F}, \lambda_{G}, s^{-c}, s_{12}^{+}, s^{+} \geq 0
\end{array}
$$

The optimal solution of the above problem is $\lambda_{C}^{*}=1, \phi^{*}=4, s^{+^{*}}=0, s_{12}^{+^{*}}=2$ , $s^{-c^{*}}=0$ and the other variables are zero. Based on part 1 of Theorem 1 , since $\phi^{*}=4>1$, DMU A is inefficient and since $s^{-c^{*}}=0$, this DMU doesn't have congestion in its input. In addition, we have $s_{12}^{+^{*}}=2$; therefore, this DMU can increase its input by two units without worsening its efficiency. For DMU B, the 
right-hand side of the first and second constraints in problem (3) is modified to 2 and $2 \phi$, respectively. In this case, the optimal solution is $\lambda_{C}^{*}=1, \phi^{*}=1$, $s^{+^{*}}=0, s_{12}^{+^{*}}=1$, and $s^{-c^{*}}=0$. This optimal solution shows that Theorem 1 is not satisfied and there is no congestion present in DMU B. Also, since $s_{12}^{+*}=1$, DMU B can increase its input by one unit without worsening its efficiency. For DMU C, the optimal solution of the modified problem is $\lambda_{C}^{*}=1, \phi^{*}=1$, $s^{+^{*}}=0, s_{12}^{+^{*}}=0$, and $s^{-c^{*}}=0$. None of the conditions of Theorem 1 is satisfied. Thus, this DMU is efficient and there is no congestion present in its input. The optimal solution of the modified problem for DMU D is $\lambda_{C}^{*}=1, \phi^{*}=2, s^{+^{*}}=0$ ,$s_{12}^{+^{*}}=0$, and $s^{-c^{*}}=2$. Since $\phi^{*}=2$ and $s^{-c^{*}}=2$, part 1 of Theorem 1 is satisfied and congestion is present in DMU D and the congestion amount in its input is $s^{-c^{*}}=2$. Finally, the results of using model (2) for all DMUs in Figure 1 , are presented in Table 1.

\begin{tabular}{|c|c|c|c|c|}
\hline DMUs & $\phi^{*}$ & $\boldsymbol{S}^{-c^{*}}$ & $\boldsymbol{S}_{12}^{+^{*}}$ & $\boldsymbol{S}^{\mathbf{+}^{*}}$ \\
\hline $\mathrm{A}$ & 4.000 & 0 & 1 & 0 \\
\hline $\mathrm{B}$ & 1.000 & 0 & 1 & 0 \\
\hline $\mathrm{C}$ & 1.000 & 0 & 0 & 0 \\
\hline $\mathrm{D}$ & 2.000 & 2 & 0 & 0 \\
\hline $\mathrm{E}$ & 1.000 & 1 & 0 & 0 \\
\hline $\mathrm{F}$ & 1.667 & 1 & 0 & 0 \\
\hline $\mathrm{G}$ & 1.667 & 1.5 & 0 & 0 \\
\hline
\end{tabular}

Table 1: Determining congestion by the BCC input relaxation model (2)

\section{Input relaxation congestion model in fuzzy DEA}

Uncertainty is inevitable and commonly exists in many decision-making problems. For this reason, the ordinary set theory has been developed into the fuzzy set theory, in which the problem of uncertainty is studied. The fuzzy set theory was first introduced by Zadeh [34], suggesting that fuzzy sets can be used as a basis for the theory of possibility similar to the way that the measure theory provides a basis for the theory of probability. More information about the possibility theory can be found in Dubois and Prade [12].

Zadeh [34] introduced a fuzzy variable, which is associated with a possibility distribution in the same manner that a random variable is associated with a 
probability distribution. Using the possibility theory, the possibilities of the fuzzy events (i.e., fuzzy constraints) can be determined. In this section, following Jahanshahloo and Khodabakhshi [17], a BCC input relaxation model for improving the output with fuzzy input and output data (FIR) is given as follows:

$$
\begin{aligned}
& \text { Maximize } \phi \\
& \text { Subject to } \quad \sum_{j=1}^{n} \lambda_{j} \widetilde{y}_{r j} \geq \phi \widetilde{y}_{r o}, \quad r=1,2, \ldots, s, \\
& \sum_{j=1}^{n} \lambda_{j} \tilde{x}_{t j}-s_{i 2}^{+} \leq \tilde{x}_{i o}, \quad i=1,2, \ldots, m \\
& \sum_{j=1}^{n} \lambda_{j}=1 \\
& s_{i 2}^{+}, \lambda_{j} \geq 0, \quad i=1,2, \ldots, m ; j=1,2, \ldots, n .
\end{aligned}
$$

The concept of chance-constrained programming (CCP), which was introduced by Charnes and Cooper [5], is adopted to solve the FIR model (4). CCP deals with uncertainty by specifying the desired levels of confidence for which the constraints hold. Using the concepts of the CCP and the possibility of the fuzzy events or fuzzy constraints, the FIR model (4) becomes the possibility input relaxation (PIR) model (5):

$$
\begin{gathered}
\text { Maximize } \quad \phi \\
\text { Subject to } \quad \pi\left(\sum_{j=1}^{n} \lambda_{j} \tilde{y}_{r j} \geq \phi \widetilde{y}_{r o}\right) \geq \beta_{r}, \quad r=1,2, \ldots, s, \\
\pi\left(\sum_{j=1}^{n} \lambda_{j} \widetilde{x}_{i j}-s_{i 2}^{+} \leq \widetilde{x}_{i o}\right) \geq \alpha_{i} \quad i=1,2, \ldots, m, \\
\sum_{j=1}^{n} \lambda_{j}=1, \\
s_{i 2}^{+}, \lambda_{j} \geq 0, \quad i=1,2, \ldots, m ; j=1,2, \ldots, n .
\end{gathered}
$$

where $\beta_{r} \in[0,1], r=1,2, \ldots, s$, and $\alpha_{i} \in[0,1], i=1,2, \ldots, m$, are prespecified acceptable levels of possibility and $\pi$ is the possibility measure from $P\left(\Theta_{i}\right)$ to $[0$, 1] in which $\Theta_{i}$ is an arbitrary set and $P\left(\Theta_{i}\right)$ is the collection of all subsets of $\Theta_{i}$ . Let $\alpha=\left[\alpha_{1}, \alpha_{2}, \ldots, \alpha_{m}, \beta_{1}, \beta_{2}, \ldots, \beta_{s}\right]$ and let us define an $\alpha$ - possibilistic efficient DMU and an $\alpha$-possibilistic inefficient DMU, as follows: 
Definition 3 (Fuzzy efficiency): DMUo with fuzzy inputs and outputs is $\alpha$ possibilistic efficient if and only if the following two conditions hold:

1) $\phi^{*}=1$,

2) The slack values are all zeros for all optimal solutions.

However, to make a reasonable efficiency comparison of the DMUs, the possibility levels of the constraints $\alpha$ in the PIR model (5) should be set at the same level. The following lemma is useful in finding the optimal solution of the possibilistic BCC (PBCC) model (5).

Lemma 1 (Lertworasirikul et al. [25]): Let $\widetilde{a}_{1}, \widetilde{a}_{2}, \ldots, \widetilde{a}_{n}$ be fuzzy variables with normal and convex membership functions. Suppose $(.)_{\alpha_{j}}^{L}$ and $(.)_{\alpha_{j}}^{U}$ denote the lower and upper bounds of the $\alpha$-level set of $\widetilde{a}_{i},(i=1,2, \ldots, m)$. Then, for any given possibility levels $\alpha_{1}, \alpha_{2}$ and $\alpha_{3}$ with $0 \leq \alpha_{1}, \alpha_{2}, \alpha_{3} \leq 1$ :

1. $\pi\left(\widetilde{a}_{1}+\tilde{a}_{2}+\ldots .+\widetilde{a}_{n} \leq b\right) \geq \alpha_{1}$ if and only if

$$
\left(\widetilde{a}_{1}\right)_{\alpha_{1}}^{L}+\left(\widetilde{a}_{2}\right)_{\alpha_{1}}^{L}+\ldots .+\left(\widetilde{a}_{n}\right)_{\alpha_{1}}^{L} \leq b,
$$

2. $\pi\left(\widetilde{a}_{1}+\widetilde{a}_{2}+\ldots .+\widetilde{a}_{n} \geq b\right) \geq \alpha_{2}$ if and only if

$$
\left(\widetilde{a}_{1}\right)_{\alpha_{2}}^{U}+\left(\widetilde{a}_{2}\right)_{\alpha_{2}}^{U}+\ldots .+\left(\widetilde{a}_{n}\right)_{\alpha_{2}}^{U} \geq b
$$

3. $\pi\left(\widetilde{a}_{1}+\widetilde{a}_{2}+\ldots .+\widetilde{a}_{n}=b\right) \geq \alpha_{3}$ if and only if

$$
\left(\widetilde{a}_{1}\right)_{\alpha_{3}}^{L}+\left(\widetilde{a}_{2}\right)_{\alpha_{3}}^{L}+\ldots .+\left(\widetilde{a}_{n}\right)_{\alpha_{3}}^{L} \leq b \text { and }\left(\widetilde{a}_{1}\right)_{\alpha_{3}}^{U}+\left(\widetilde{a}_{2}\right)_{\alpha_{3}}^{U}+\ldots .+\left(\widetilde{a}_{n}\right)_{\alpha_{3}}^{U} \geq b \text {. }
$$

The PBCC model (5) can be transformed into:

\section{Maximize $\quad \phi$}

$$
\begin{gathered}
\text { Subject to } \quad \pi\left(\sum_{j=1}^{n} \lambda_{j} \tilde{y}_{r j}-\phi \widetilde{y}_{r o} \geq 0\right) \geq \beta_{r}, \quad r=1,2, \ldots, s, \\
\pi\left(\sum_{j=1}^{n} \lambda_{j} \widetilde{x}_{i j}-\widetilde{x}_{i o} \leq s_{i 2}^{+}\right) \geq \alpha_{i} \quad i=1,2, \ldots, m, \\
\quad \sum_{j=1}^{n} \lambda_{j}=1, \\
s_{i 2}^{+}, \lambda_{j} \geq 0, \quad i=1,2, \ldots, m ; j=1,2, \ldots, n .
\end{gathered}
$$

Depending upon the membership functions of the fuzzy parameters in model (6), the model may take the form of a linear programming or a nonlinear one. Based 
on lemma 1 and following Liu [26], for a trapezoidal fuzzy number $\left[\left(r_{i}\right)_{\circ}^{L},\left(r_{i}\right)_{1}^{L},\left(r_{i}\right)_{1}^{U},\left(r_{i}\right)_{\circ}^{U}\right], i=1,2, \ldots, m$, and any given possibility level $\alpha, 0 \leq \alpha \leq 1$ the following relations hold:

1) $\pi\left(\widetilde{r}_{1}+\widetilde{r}_{2}+\ldots .+\widetilde{r}_{n} \leq b\right) \geq \alpha$ if and only if

$$
(1-\alpha)\left[\left(\widetilde{r}_{1}\right)_{\circ}^{L}+\left(\widetilde{r}_{2}\right)_{\circ}^{L}+\ldots+\left(\widetilde{r}_{n}\right)_{0}^{L}\right]+\alpha\left[\left(\widetilde{r}_{1}\right)_{1}^{L}+\left(\widetilde{r}_{2}\right)_{1}^{L} \ldots+\left(\widetilde{r}_{n}\right)_{1}^{L}\right] \leq b
$$

2) $\pi\left(\widetilde{r}_{1}+\widetilde{r}_{2}+\ldots+\widetilde{r}_{n} \geq b\right) \geq \alpha$ if and only if

$$
(1-\alpha)\left[\left(\widetilde{r}_{1}\right)_{\circ}^{U}+\left(\widetilde{r}_{2}\right)_{\circ}^{U}+\ldots+\left(\widetilde{r}_{n}\right)_{\circ}^{U}\right]+\alpha\left[\left(\widetilde{r}_{1}\right)_{1}^{U}+\left(\widetilde{r}_{2}\right)_{1}^{U}+\ldots+\left(\widetilde{r}_{n}\right)_{1}^{U}\right] \geq b
$$

3) $\pi\left(\widetilde{r}_{1}+\widetilde{r}_{2}+\ldots+\widetilde{r}_{n}=b\right) \geq \alpha$ if and only if

$$
\begin{aligned}
& (1-\alpha)\left[\left(\widetilde{r}_{1}\right)_{\circ}^{L}+\left(\widetilde{r}_{2}\right)_{\circ}^{L}+\ldots+\left(\widetilde{r}_{n}\right)_{\circ}^{L}\right]+\alpha\left[\left(\widetilde{r}_{1}\right)_{1}^{L}+\left(\widetilde{r}_{2}\right)_{1}^{L}+\ldots+\left(\widetilde{r}_{n}\right)_{1}^{L}\right] \leq b \\
& (1-\alpha)\left[\left(\widetilde{r}_{1}\right)_{\circ}^{U}+\left(\widetilde{r}_{2}\right)_{\circ}^{U}+\ldots+\left(\widetilde{r}_{n}\right)_{\circ}^{U}\right]+\alpha\left[\left(\widetilde{r}_{1}\right)_{1}^{U}+\left(\widetilde{r}_{2}\right)_{1}^{U}+\ldots+\left(\widetilde{r}_{n}\right)_{1}^{U}\right] \geq b .
\end{aligned}
$$

Therefore, when inputs and outputs are trapezoidal fuzzy numbers, by adding the slack variables, model (6) becomes a linear programming model, as follows:

$$
\text { Maximize } \quad \phi+\varepsilon\left(\sum_{i=1}^{m} s_{i 1}^{-}-\sum_{i=1}^{m} s_{i 2}^{+}+\sum_{r=1}^{s} s_{r}^{+}\right)
$$

Subject to $\quad\left(1-\beta_{r}\right)\left(\sum_{j=1}^{n} \lambda_{j} \widetilde{y}_{r j}-\phi \widetilde{y}_{r o}\right)_{0}^{\mathrm{U}}+\beta_{r}\left(\sum_{j=1}^{n} \lambda_{j} \widetilde{y}_{r j}-\phi \widetilde{y}_{r o}\right)_{1}^{\mathrm{U}}-s_{r}^{+}=0$,

$$
\begin{gathered}
r=1,2, \ldots, s, \\
\left(1-\alpha_{i}\right)\left(\sum_{j=1}^{n} \lambda_{j} \tilde{x}_{i j}-\widetilde{x}_{i o}\right)_{0}^{\mathrm{L}}+\alpha_{i}\left(\sum_{j=1}^{n} \lambda_{j} \tilde{x}_{i j}-\tilde{x}_{i o}\right)_{1}^{\mathrm{L}}+s_{i 1}^{-}-s_{i 2}^{+}=0, i=1,2, \ldots, m,
\end{gathered}
$$

$$
\sum_{j=1}^{n} \lambda_{j}=1
$$

$$
s_{i 1}^{-}, s_{i 2}^{+}, s_{r}^{+}, \lambda_{j} \geq 0, i=1,2, \ldots, m ; r=1,2, \ldots, s ; j=1,2, \ldots, n .
$$

Model (7) is a generalization of the BCC model (1) with fuzzy inputs and outputs. In a similar way, one can generalize the one-model approach to congestion presented in model (2) to the following version:

$$
\text { Maximize } \quad \phi+\varepsilon\left(\sum_{r=1}^{s} s_{r}^{+}-\sum_{i=1}^{m} s_{i}^{-c}-\sum_{i=1}^{m} s_{i 2}^{+}\right)
$$

Subject to $\quad\left(1-\beta_{r}\right)\left(\sum_{j=1}^{n} \lambda_{j} \widetilde{y}_{r j}-\phi \widetilde{y}_{r o}\right)_{0}^{\mathrm{U}}+\beta_{r}\left(\sum_{j=1}^{n} \lambda_{j} \widetilde{y}_{r j}-\phi \widetilde{y}_{r o}\right)_{1}^{\mathrm{U}}-s_{r}^{+}=0$,

$$
r=1,2, \ldots, s,
$$




$$
\begin{gathered}
\left(1-\alpha_{i}\right)\left(\sum_{j=1}^{n} \lambda_{j} \tilde{x}_{i j}-\tilde{x}_{i o}\right)_{0}^{\mathrm{L}}+\alpha_{i}\left(\sum_{j=1}^{n} \lambda_{j} \widetilde{x}_{i j}-\widetilde{x}_{i o}\right)_{1}^{\mathrm{L}}+s_{i}^{-c}-s_{i 2}^{+}=0, \\
i=1,2, \ldots, m, \\
\sum_{j=1}^{n} \lambda_{j}=1, \\
s_{i}^{-c}, s_{i 2}^{+}, s_{r}^{+}, \lambda_{j} \geq 0, i=1,2, \ldots, \mathrm{m} ; r=1,2, \ldots, s ; j=1,2, \ldots, n .
\end{gathered}
$$

Therefore, we have the following theorem as an obvious generalization of Theorem 1 :

Theorem 2: Suppose $\left(\phi^{*}, \lambda^{*}, s_{i}^{-c^{*}}, s_{i 2}^{+^{*}} s_{r}^{+^{*}}\right)$ is the optimal solution of model (8). Then, at the possibility level $\alpha$, DMUo has input congestion if and only if at least one of the following conditions is satisfied:

1) $\phi^{*}>1$, and there exists at least one $s_{i}^{-c *}>0$, for $i=1,2, \ldots, m$.

2) There exists at least one $s_{r}^{+*}>0$, for $r=1,2, \ldots, s$, also one $s_{i}^{-c^{* *}}>0$, for $i=$ $1,2, \ldots, m$.

\section{Fuzzy numerical example}

We present a numerical experiment to apply the possibility approach to identify the input congestion via the BCC input relaxation model (8), when inputs and outputs are fuzzy numbers. The example is taken from Guo and Tanaka [18]. The fuzzy inputs and fuzzy outputs are given in Table 2. These fuzzy inputs and outputs have symmetrical triangular membership functions, a special case of the trapezoidal membership functions. The membership functions are denoted by (c, d) where $\mathrm{c}$ is the center and $\mathrm{d}$ is the spread. In this example, all the fuzzy constraints are satisfied with the same possibility level, i.e, $\beta_{1}=\beta_{2}=\ldots=\beta_{s}=\alpha_{1}=\alpha_{2}=\ldots=\alpha_{m}$.

\begin{tabular}{|c|c|c|c|c|c|}
\hline DMU & DMU1 & DMU2 & DMU3 & DMU4 & DMU5 \\
\hline Input 1 & $(4,0.5)$ & $(2.9,0)$ & $(6.9,0.5)$ & $(4.1,0.7)$ & $(8.5,0.6)$ \\
\hline Input 2 & $(5.1,0.2)$ & $(1.5,0.1)$ & $(8.6,0.4)$ & $(2.3,0.4)$ & $(7.1,0.5)$ \\
\hline Output 1 & $(4.6,0.2)$ & $(5.2,0)$ & $(3.2,0.3)$ & $(2.9,4)$ & $(5.1,0.7)$ \\
\hline Output 2 & $(4.1,0.3)$ & $(4.5,0.2)$ & $(5.1,0.8)$ & $(5.7,0.2)$ & $(7.4,0.9)$ \\
\hline
\end{tabular}

Table 2: DMUs with two fuzzy inputs and two fuzzy outputs 
The results for the possibility levels $0,0.25,0.5,0.75$, and 1 are provided in Table 3. In this Table, the numbers in parentheses represent the efficiency value, the inputs congestions of the corresponding $\left(\phi^{*}, s_{1}^{-c^{*}}, s_{2}^{-c^{*}}\right)$, evaluated at the given possibility level $\alpha$. The interpretation of the results is as follows. At the possibility level 1, DMU2 and DMU5 are possibilistically efficient and DMU1, DMU3, and DMU4 are possibilistically inefficient, and their congestion values corresponding to the first input are $0.26,0.455$, and 0.43 , respectively. Note that in the second input, there is no congestion for these DMUs. From Table 3, DMU2 and DMU5 are possibilistically efficient at all the possibility levels, whereas DMU3 and DMU4 are possibilistically inefficient at some possibility levels. In addition, for DMU3 and DMU4 there is congestion at some possibility levels, and DMU1 is inefficient at all the possibility levels.

\begin{tabular}{|c|c|c|c|c|c|}
\hline$\alpha$ & DMU1 & DMU2 & DMU3 & DMU4 & DMU5 \\
\hline 0 & $(1.072,0,0)$ & $(1,0,0)$ & $(1,0,0)$ & $(1,0,0)$ & $(1,0,0)$ \\
\hline 0.25 & $(1.079,0.226,0)$ & $(1,0,0)$ & $(1,0,0)$ & $(1,0,0)$ & $(1,0,0)$ \\
\hline 0.5 & $(1.088,0,0)$ & $(1,0,0)$ & $(1,0,0)$ & $(1,0,0)$ & $(1,0,0)$ \\
\hline 0.75 & $(1.092,0.18,0)$ & $(1,0,0)$ & $(1.057,0.494,0)$ & $(1,0,0)$ & $(1,0,0)$ \\
\hline 1 & $(1.096,0.260,0)$ & $(1,0,0)$ & $(1.057,0.455,0)$ & $(1.1,0.43,0)$ & $(1,0,0)$ \\
\hline
\end{tabular}

Table 3: The results of the efficiency values and congestion at 5 possibility levels

\section{Empirical example}

Now, we apply the fuzzy congestion model (8) to identify the input congestion; to this end, we employ the technical data for 16 hospitals, which are presented in Table 4. These fuzzy inputs and fuzzy outputs have symmetrical triangular membership functions. The data set is taken from Tone and Sahoo [31]. The inputs are the total hours worked by doctors in the survey period (I1), total hours worked by nurses (I2), total hours worked by technical workers (I3), and total hours worked by office staff (I4). The outputs are the total medical insurance points for outpatients (O1) and the total medical insurance points for inpatients $(\mathrm{O} 2)$. 


\begin{tabular}{|c|c|c|c|c|c|c|c|}
\hline $\begin{array}{c}\text { DM- } \\
\text { Us }\end{array}$ & $\begin{array}{c}\text { Hospi- } \\
\text { tals }\end{array}$ & I1 & I2 & I3 & I4 & O1 & O2 \\
\hline 1 & H1 & $(995,17)$ & $(6205,262)$ & $(1375,35)$ & $(2629,49)$ & $(4127,83)$ & $(1678,17)$ \\
\hline 2 & H2 & $(917,15)$ & $(5898,248)$ & $(1379,37)$ & $(2047,37)$ & $(3721,77)$ & $(1277,13)$ \\
\hline 3 & H3 & $(3178,91)$ & $(10049,349)$ & $(3615,85)$ & $(3511,61)$ & $(2706,27)$ & $(2051,20)$ \\
\hline 4 & H4 & $(813,14)$ & $(5833,233)$ & $(1124,34)$ & $(1730,27)$ & $(2176,21)$ & $(1538,15)$ \\
\hline 5 & H5 & $(1236,21)$ & $(8639,309)$ & $(2486,56)$ & $(4990,92)$ & $(5220,105)$ & $(20426,204)$ \\
\hline 6 & H6 & $(1146,11)$ & $(7610,289)$ & $(1600,30)$ & $(3589,59)$ & $(3517,65)$ & $(1856,19)$ \\
\hline 7 & H7 & $(705,13)$ & $(5600,200)$ & $(1557,27)$ & $(3623,63)$ & $(2352,24)$ & $(20606,206)$ \\
\hline 8 & H8 & $(2871,89)$ & $(11524,404)$ & $(2880,51)$ & $(2452,52)$ & $(1755,18)$ & $(1664,17)$ \\
\hline 9 & H9 & $(1089,20)$ & $(8998,228)$ & $(1730,40)$ & $(2823,53)$ & $(4412,89)$ & $(2334,24)$ \\
\hline 10 & H10 & $(2032,52)$ & $(9383,243)$ & $(2421,47)$ & $(4454,84)$ & $(5386,111)$ & $(2080,21)$ \\
\hline 11 & H11 & $(1414,24)$ & $(10468,263)$ & $(2140,57)$ & $(3649,69)$ & $(5735,118)$ & $(2691,27)$ \\
\hline 12 & H12 & $(1967,29)$ & $(11260,272)$ & $(2759,69)$ & $(3178,48)$ & $(6079,125)$ & $(2804,29)$ \\
\hline 13 & H13 & $(1851,28)$ & $(9880,250)$ & $(2335,55)$ & $(4570,90)$ & $(5893,113)$ & $(2495,26)$ \\
\hline 14 & H14 & $(3100,102)$ & $(15649,479)$ & $(5487,127)$ & $(2940,55)$ & $(5248,103)$ & $(3692,37)$ \\
\hline 15 & H15 & $(5016,176)$ & $(18010,480)$ & $(4008,98)$ & $(3567,60)$ & $(7800,131)$ & $(4582,47)$ \\
\hline 16 & H16 & $(1924,35)$ & $(12682,452)$ & $(2490,63)$ & $(2975,53)$ & $(6040,123)$ & $(3396,35)$ \\
\hline
\end{tabular}

Note: I1, I2, I3, and I4 denote the inputs; O1 and O2 denote the outputs.

Table 4: Imprecise data for four inputs and two outputs, for 16 hospitals

The computational results of the BCC input relaxation model (8) for determining the input congestion of hospitals are shown in Table 5 . The first column of Table 5 shows the hospital's number and columns 2,3 , and 4 show the computational results of model (8) at the possibility levels of $0,0.5$, and 1 , respectively. In Table 5 , the numbers in parentheses are the efficiency score, $\phi^{*}$, the congestion of the third and fourth input $\left(s_{3}^{-c^{*}}\right.$ and $\left.s_{4}^{-c^{*}}\right)$, and the slacks of the outputs $\left(s_{1}^{+^{*}}\right.$ and $\left.s_{2}^{+*}\right)$ in evaluating the hospitals. The congestion for the first and second inputs for all of the hospitals has not been shown, due to their absence. Based on the results provided in Table 5, hospitals 5, 7, and 15 have the optimal solutions $\phi^{*}=1, s_{3}^{-c^{*}}=0, s_{4}^{-c^{*}}=0, s_{1}^{+^{*}}=0$, and $s_{2}^{+^{*}}=0$; so these hospitals don't have input congestion. The other hospitals with the efficiency score of $\phi^{*}>1$ are inefficient at all the possibility levels. In fact, in efficient units, the score of efficiency $\phi^{*}$, is equal to one and all the slacks of input and output, including $s^{-c^{*}}=0$, congestion, are zero. 


\begin{tabular}{|c|c|c|c|}
\hline \multirow{2}{*}{ Hospitals } & \multicolumn{2}{|c|}{$\left(\phi^{*}, s_{3}^{-c^{*}}, s_{4}^{-c^{*}}, s_{1}^{+^{*}}, s_{2}^{+^{*}}\right)$ with possibility level $\alpha$} \\
\cline { 2 - 4 } & $\alpha=0$ & $\alpha=0.5$ & $\alpha=1$ \\
\hline H1 & $(1.88,0,0,0,1436)$ & $(1.89,0,0,0,1423)$ & $(1.89,0,0,0,1411)$ \\
\hline H2 & $(2.09,0,0,0,1935)$ & $(2.09,0,0,0,1920)$ & $(2.10,0,0,0,1905)$ \\
\hline H3 & $(2.83,0,0,0,0)$ & $(2.82,0,0,0,0)$ & $(2.81,0,0,0,0)$ \\
\hline H4 & $(3.54,0,0,0,0)$ & $(3.53,0,0,0,0)$ & $(3.52,0,0,0,0)$ \\
\hline H5 & $(1,0,0,0,0)$ & $(1,0,0,0,0)$ & $(1,0,0,0,0)$ \\
\hline H6 & $(2.21,0,23,0,478)$ & $(2.22,0,23,0,471)$ & $(2.22,0,22,0,466)$ \\
\hline H7 & $(1,0,0,0,0)$ & $(1,0,0,0,0)$ & $(1,0,0,0,0)$ \\
\hline H8 & $(4.24,0,0,0,0)$ & $(4.23,0,0,0,0)$ & $(4.22,0,0,0,0)$ \\
\hline H9 & $(1.76,0,0,0,474)$ & $(1.76,0,0,0,466)$ & $(1.77,0,0,0,456)$ \\
\hline H10 & $(1.44,0,863,0,1599)$ & $(1.45,0,875,0,1584)$ & $(1.45,0,887,0,1570)$ \\
\hline H11 & $(1.36,0,73,0,946)$ & $(1.35,0,78,0,934)$ & $(1.36,0,82,0,922)$ \\
\hline H12 & $(1.28,0,0,0,1001)$ & $(1.28,0,0,0,993)$ & $(1.28,0,0,0,984)$ \\
\hline H13 & $(1.32,0,973,0,1300)$ & $(1.32,0,988,0,1290)$ & $(1.32,0,1003,0,1280)$ \\
\hline H14 & $(1.46,1524,0,0,0)$ & $(1.46,1750,0,0,0)$ & $(1.46,1557,0,0,0)$ \\
\hline H15 & $(1,0,0,0,0)$ & $(1,0,0,0,0)$ & $(1,0,0,0,0)$ \\
\hline H16 & $(1.29,0,0,0,214)$ & $(1.29,0,0,0,205)$ & $(1.29,0,0,0,196)$ \\
\hline
\end{tabular}

Table 5: The results of efficiency values and input congestion at 3 possibility levels

As we can see from Table 5, hospital 6 has an efficiency score of more than one, which means that this hospital is inefficient at all the possibility levels. At the possibility level $\alpha=0$, the optimal solution of this hospital is $\phi^{*}=2.21$, $s_{3}^{-c^{*}}=0, s_{4}^{-c^{*}}=23, s_{1}^{+^{*}}=0$, and $s_{2}^{+^{*}}=478$. This optimal solution satisfies condition (1) of Theorem 2, so in the performance evaluation of hospital 6 , the fourth input, namely, the total hours worked by office staff, has congestion, and the amount of its congestion is $s_{4}^{-c^{*}}=23$.

The results provided in Table 5 also show that hospital 10 with $\phi^{*}>1$ is inefficient at all the possibility levels. At the possibility level zero, the optimal solution of this hospital is $\phi^{*}=1.44, s_{3}^{-c^{*}}=0, s_{4}^{-c^{*}}=863, s_{1}^{+^{*}}=0$, and $s_{2}^{+*}=1599$. This optimal solution satisfies condition (1) of Theorem 2, so in the performance evaluation of hospital 10, the fourth input has congestion and the amount of its congestion is $s_{4}^{-c^{*}}=863$.

Hospital 11 with $\phi^{*}>1$ is inefficient at all the possibility levels. At the possibility level zero, the optimal solution of this hospital is $\phi^{*}=1.36, s_{3}^{-c^{*}}=0, s_{4}^{-c^{*}}=73$ 
, $s_{1}^{+^{*}}=0$, and $s_{2}^{+^{*}}=946$. This optimal solution satisfies condition (1) of Theorem 2, so in the performance evaluation of hospital 11, the fourth input has congestion and the amount of its congestion is $s_{4}^{-c^{*}}=73$.

Hospital 13 with $\phi^{*}>1$ is inefficient at all the possibility levels. At the possibility level zero, the optimal solution of this hospital is $\phi^{*}=1.32, s_{3}^{-c^{*}}=0$, $s_{4}^{-c^{*}}=973, s_{1}^{+^{*}}=0$, and $s_{2}^{+^{*}}=1300$. This optimal solution satisfies condition (1) of Theorem 2, so in the performance evaluation of hospital 13, the fourth input has congestion and the amount of its congestion is $s_{4}^{-c^{*}}=973$.

Finally, hospital 14 with $\phi^{*}>1$ is inefficient at all the possibility levels. At the possibility level zero, the optimal solution of this hospital is $\phi^{*}=1.46$, $s_{3}^{-c^{*}}=1524, s_{4}^{-c^{*}}=0, s_{1}^{+^{*}}=0$, and $s_{2}^{+^{*}}=0$. This optimal solution satisfies condition (1) of Theorem 2, so in the performance evaluation of hospital 14, the third input, namely, the total hours worked by technical workers, has congestion and the amount of its congestion is $s_{3}^{-c^{*}}=1524$. At the possibility levels of 0 , 0.5 , and 1, the amount of congestion in the third input of hospital 14 is 1542 , 1750 , and 1557 , respectively.

\section{Conclusion}

Congestion is a widely observed phenomenon that indicates an economic state where inputs are overly invested [33]. The requirement to study congestion is, therefore, rather obvious; furthermore, it has additional important practical implications, especially when its use is associated with a need for increasing inputs to serve vital objectives besides output maximization [10]. As such, in time, congestion has developed into a topic that has received considerable attention from both researchers and practitioners alike. And while there are some debates on the subject of congestion [6-9, 13], most of them arise due to the fact that the different models proposed to identify congestion work under different assumptions.

In the existing literature on DEA, many models have been introduced to identify the input congestion of DMUs. Among these models, the most famous one, which is called the one-model approach, was introduced by Cooper et al. [11] and further expanded into the BCC input relaxation model. On the other hand, uncertainty is inevitable and commonly exists in many decision-making problems. For this reason, the fuzzy set theory has been proposed as a way to quantify imprecise and vague data in DEA models.

In this paper, we proposed a BCC input relaxation model with precise and imprecise data for determining the input congestion of DMUs in the mathematical programming technique of DEA with the one-model approach that has been introduced by Cooper et al. [11]. Furthermore, the possibility theory is used to 
determine the possibilities of the fuzzy constraints. We have solved the fuzzy models by using the concept of chance-constrained programming, which has been introduced by Charnes and Cooper in 1959 [5].

The proposed one-model approach was further applied to determine the input congestion of 16 hospitals, wherein each hospital used four fuzzy inputs to produce two fuzzy outputs. These fuzzy inputs and outputs have symmetrical triangular membership functions.

Identifying the input congestion with the input relaxation model and fuzzy inputs and outputs and solving it with the possibility approach is a new work that has been presented in this article.

For future extensions, how to develop the proposed model with fuzzy random data will be an important research issue. Finally, it is hoped that this research makes a contribution to the field of DEA.

\section{Acknowledgement}

The authors would like to thank the Editor-in-Chief and the two anonymous reviewers for their very helpful comments and suggestions made on the previous draft of this manuscript.

\section{References}

[1] Banker, R. D., Charnes, A., and Cooper, W. W. (1984). Some models for estimating technical and scale inefficiencies in data envelopment analysis. Management Science, 30, 1078-1092.

[2] Charles, V. and Kumar, M. (2014). Satisficing data envelopment analysis: an application to SERVQUAL efficiency. Measurement, 51, 71-80.

[3] Charles, V., Peretto, C., and Gherman, T. (2016). Technical efficiency analytics for the public banks in Argentina. ICPE Public Enterprise HalfYearly Journal, 22(1), 118-139.

[4] Charnes, A., Cooper, W. W., and Rhodes, E. (1978). Measuring the efficiency of decision making units. European Journal of Operational Research, 2(6), pp. 429-444.

[5] Charnes A. and Cooper, W. W. (1959). Chance-constrained programming. Management Science, 6, 73-79.

[6] Cherchye, L., Kuosmanen, T., and Post, T. (2001). Alternative treatments of congestion in DEA-a rejoinder to Cooper, Gu and Li. European Journal of Operational Research, 132, 75-80.

[7] Cooper, W. W., Gu, B. S., and Li, S. L. (2001). Note: Alternative treatments of congestion in DEA-a response to the Cherchye, Kuosmanen and Post critique. European Journal of Operational Research, 132, 81-87. 
[8] Cooper, W. W., Seiford, L. M., and Tone, K. (2000). In: Data Envelopment Analysis. Kluwer Academic Publishers, Boston, Dordrecht, London, pp. 7273.

[9] Cooper W. W., Seiford, L. M., and Zhu, J. (2000). A unified additive model approach for evaluating inefficiency and congestion with associated measures in DEA. Socio-Economic Planning Sciences, 34, 1-25.

[10] Cooper, W. W., Deng, H., Huang, Z., and Li, S. X. (2004). Chance constrained programming approaches to congestion in stochastic data envelopment analysis. European Journal of Operational Research, 155, 487-501.

[11] Cooper, W. W., Deng, H., Huang, Z., and Li, S. X. (2002). A one-model approach to congestion in data envelopment analysis. Socio-Economic Planning Sciences, 36, 231-238.

[12] Dubois D., \& Prade, H. (1988). Possibility Theory: An Approach to Computerized Processing of Uncertainty. New York, NY: Plenum Press.

[13] Färe, R. and Grosskopf, S., (2000). Slacks and congestion: a response. SocioEconomic Planning Sciences, 34, 35-50.

[14] Färe, R. and Grosskopf S. (2001). When can slacks be used to identify congestion? An answer to W. W. Cooper, L. Seiford and J. Zhu, Socio-Economic Planning Sciences, 35(3), 217-221.

[15] Flegg, A. T. and Allen, D. O. (2009). Congestion in the new British universities: a further analysis. Journal of the Operations Research Society of Japan, 52(2), 186-203.

[16] Hosseinzadeh Lotfi, F., Mohammad Pourzarandi, M. E., Ahadzadeh Namin, M., Jahantighey, M. A., and Abolghasemzadeh, Sh. (2007). Congestion in stochastic DEA for restructure strategy: an application to Iranian commercial banks. International Mathematical Forum, 2(64), 3169-3180.

[17] Jahanshahloo, G. R. and Khodabakhshi, M. (2004). Suitable combination of inputs for improving outputs in DEA with determining input congestion considering textile industry of China. Applied Mathematics and Computation, 151, 263-273.

[18] Guo, P. and Tanaka, H. (2001). Fuzzy DEA: A perceptual evaluation method. Fuzzy Sets and Systems, 119, 149-160.

[19] Kheirollahi, H., Karami Matin, B., Mahboubi, M., and Mirzaei Alavijeh, M. (2015). Chance constrained input relaxation to congestion in stochastic DEA: an application to Iranian hospitals. Global Journal of Health Science, 7(4), $151-160$.

[20] Khodabakhshi, M. (2009). A one-model approach based on relaxed combinations of inputs for evaluating input congestion in DEA. Journal of Computational and Applied Mathematics, 230(2), 443-450.

[21] Khodabakhshi, M. and Asgharian, M. (2009). An input relaxation measure of efficiency in stochastic data envelopment analysis. Applied Mathematical Modelling, 33, 2010-2023. 
[22] Khodabakhshi, M., Gholami, Y., and Kheirollahi, H. (2010). An additive model approach for estimating returns to scale in imprecise data envelopment analysis. Applied Mathematical Modelling, 34, 1247-1257.

[23] Khodabakhshi, M. and Hejrizadeh, M. (2010). An input relaxation measure of efficiency in fuzzy data envelopment analysis (FDEA). Journal of Intelligent and Fuzzy Systems, 21, 395-403.

[24] Khodabakhshi, M., Hosseinzadeh Lotfia, F., and Aryavash, K. (2014). Review of input congestion estimating methods in DEA. Journal of Applied Mathematics, 2014, Article ID 963791. Available at : http://www.hindawi.com/jour nals/jam/2014/963791/

[25] Lertworasirikul, S., Fanga, S-C., Joines, J. A., and Nuttlea, H. L. W. (2003). Fuzzy data envelopment analysis (DEA): a possibility approach. Fuzzy Sets and Systems, 139, 379-394.

[26] Liu, B. (1999). Uncertain Programming. New York, NY: Wiley-Interscience Publication.

[27] Noura, A. A., Hosseinzadeh Lotfi, F., Jahanshahloo, G. R., Fanati Rashidi, S., and Parker B. R. (2010). A new method for measuring congestion in data envelopment analysis. Socio-Economic Planning Sciences, 44, 240-246.

[28] Rostamy-Malkhalifeh, M., Ebrahimkhani Ghazi, S., Saleh, H., and Ebrahimkhani Ghazi, N. (2011). Congestion in DEA model with fuzzy data. International Journal of Applied Operational Research, 1(2), 49-56.

[29] Saljooghi, F. H. and Rayeni, M. M. (2011). Distinguishing congestion and technical inefficiency in presence undesirable output. American Journal of Applied Sciences, 8(9), 903-909.

[30] Shiraz, R. K., Charles, V., and Jalalzadeh, L. (2014). Fuzzy rough DEA model: a possibility and expected value approaches. Expert Systems with Applications, 41(2), 434-444.

[31] Tone, K. and Sahoo, B. K. (2004). Degree of scale economies and congestion: a unified DEA approach. European Journal of Operational Research, 158(3), $755-772$.

[32] Tsolas, I. E. and Charles, V. (2015). Incorporating risk into bank efficiency: a satisficing DEA approach to assess the Greek banking crisis. Expert Systems with Applications, 42(7), 3491-3500.

[33] Wei, Q. and Yan, H. (2004). Congestion and returns to scale in data envelopment analysis. European Journal of Operational Research, 153, 641-660.

[34] Zadeh, L. A. (1978). Fuzzy sets as a basis for a theory of possibility. Fuzzy Sets and Systems, 1, 3-28. 